\title{
The Reaction of Cobaloximes with Hydrogen: Products and Thermo- dynamics
}

\author{
Deven P. Estes ${ }^{\dagger}$, David C. Grills ${ }^{\ddagger}$, Jack R. Norton ${ }^{\dagger *}$ \\ 'Department of Chemistry, Columbia University, 3000 Broadway, New York, NY, 10027 \\ ${ }^{\ddagger}$ Chemistry Department, Brookhaven National Laboratory, P.O. Box 5000, Upton, NY 11973-5000
}

Supporting Information Placeholder

\begin{abstract}
A cobalt hydride has been proposed as an intermediate in many reactions of the $\operatorname{Co}\left(\mathrm{dmgBF}_{2}\right)_{2} \mathrm{~L}_{2}$ system, but its observation has proven difficult. We have observed the UV-vis spectra of $\mathrm{Co}\left(\mathrm{dmgBF}_{2}\right)_{2} \mathrm{~L}_{2}(\mathbf{1})$ in $\mathrm{CH}_{3} \mathrm{CN}$ under hydrogen pressures up to $70 \mathrm{~atm}$. A Co(I) compound (6), with an exchangeable proton, is eventually formed. We have determined the bond dissociation free energy and $\mathrm{p} K_{\mathrm{a}}$ of the new $\mathrm{O}-\mathrm{H}$ bond in $\mathbf{6}$ to be $50.5 \mathrm{kcal} / \mathrm{mol}$ and 13.4 , respectively, in $\mathrm{CH}_{3} \mathrm{CN}$, matching previous reports.
\end{abstract}

In addition to being functional $\mathrm{B}_{12}$ models ${ }^{1}$ and catalyzing the production of hydrogen from protons and electricity, ${ }^{2}$ cobaloximes catalyze $\mathrm{H} \bullet$ transfer from $\mathrm{H}_{2}{ }^{3} \mathrm{Co}\left(\mathrm{dmgBF}_{2}\right)_{2} \mathrm{~L}_{2}$ (1) and $\mathrm{Co}(\mathrm{dmgH})_{2} \mathrm{~L}_{2}$ (2) (dmg = dimethylglyoximato; $\mathrm{L}=$ $\mathrm{H}_{2} \mathrm{O}, \mathrm{CH}_{3} \mathrm{CN}$, etc.) can, under $\mathrm{H}_{2}$, transfer $\mathrm{H} \bullet$ to stable radicals such as TEMPO (Scheme 1) ${ }^{4}$ and generate radicals by $\mathrm{H} \bullet$ transfer to activated alkenes ${ }^{4}$ and alkynes. ${ }^{5}$ The cobaloxime 1 can thus generate radicals from $\alpha$-substituted acrylate esters, and catalyze radical cyclohydrogenation reactions. ${ }^{4}$ The reaction of $1, \mathrm{H}_{2}$ gas, and TEMPO is independent of [TEMPO], first order in $\mathrm{H}_{2}$, and second order in 1, suggesting that its ratedetermining step involves an $\mathrm{H}_{2}$ and two equiv of $\mathbf{1}$ (the forward reaction of eq 1$) .4$

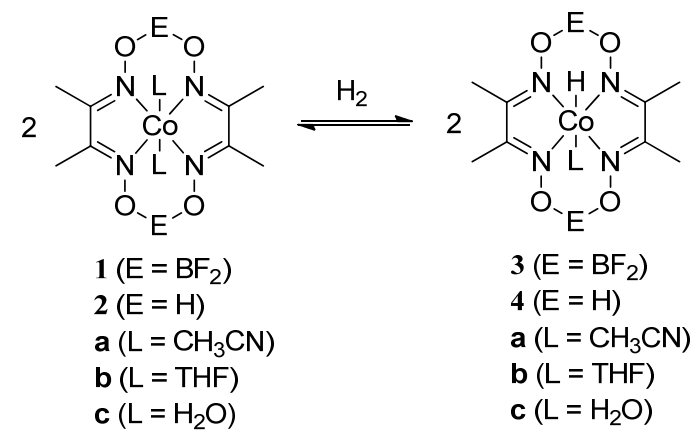

When 1 and 2 catalyze the production of $\mathrm{H}_{2}$ from protons (Scheme 2), 2a, b, 6 cobaloxime hydrides 3 have been proposed as key intermediates, although they have never been directly observed. Little is known about their structure, spectroscopy, and reactivity.
Scheme 1. Hydrogen atom transfer (HAT) from $\mathrm{H}_{2}$ to stable free radicals $\left(\mathrm{X} \bullet=\cdot \mathrm{CAr}_{3}\right.$ or TEMPO) catalyzed by $\mathbf{1}$

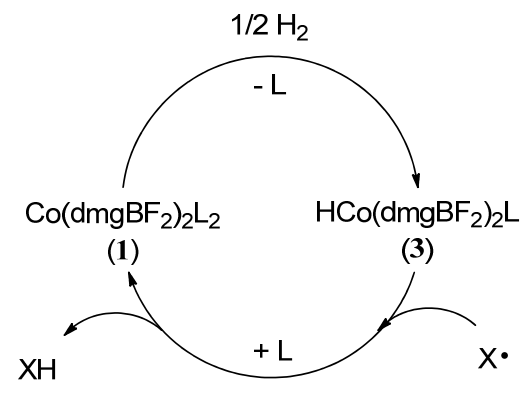

We have therefore attempted to determine the spectroscopic and thermodynamic properties (i.e. the $\mathrm{p} K_{\mathrm{a}}$, the bond dissociation free energy (BDFE), etc.) of the hydrides of 1 in various solvents. In this paper, we report the behavior of 1 under relatively high hydrogen pressures (70 atm) and use our findings to assess other observations in the literature about the $1 / \mathrm{H}_{2}$ system.

Scheme 2. Electrocatalytic production of $\mathrm{H}_{2}$ with $\mathbf{1}$

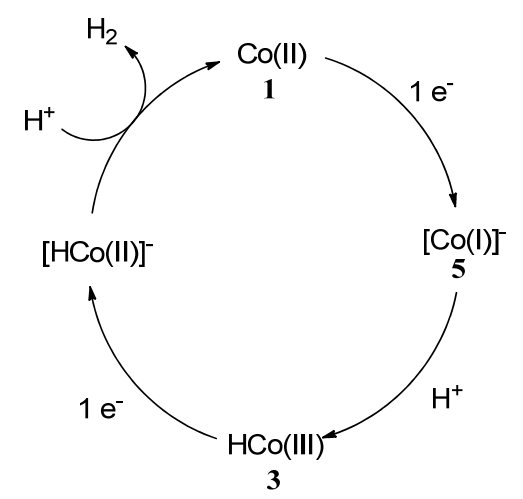

When $1 \mathrm{c}$ is dissolved in $\mathrm{CH}_{3} \mathrm{CN}$ it gives complex $1 \mathrm{a},{ }^{6 \mathrm{c}, 7}$ with $\lambda_{\max }$ at $434 \mathrm{~nm}\left(3240 \mathrm{M}^{-1} \mathrm{~cm}^{-1}\right)$. Under 70 atm of $\mathrm{H}_{2}$ at room temperature its UV-vis spectrum changes slowly (24 h) but smoothly (Figure 1) into one with a $\lambda_{\max }$ at $556 \mathrm{~nm}(7700$ $\left.\mathrm{M}^{-1} \mathrm{~cm}^{-1}\right)$, another at $627 \mathrm{~nm}\left(7460 \mathrm{M}^{-1} \mathrm{~cm}^{-1}\right)$, and a small peak at $354 \mathrm{~nm}$. The process is reversible; the original spectrum returns slowly (48 h) after release of the gas pressure. 


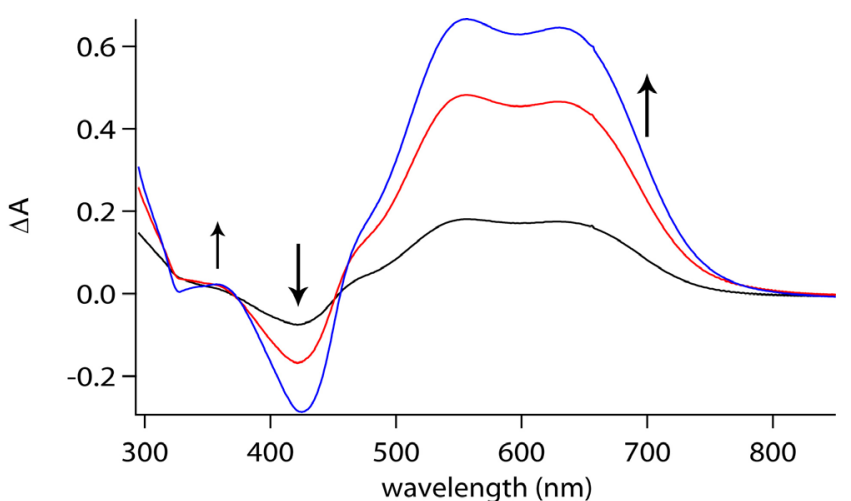

Figure 1. UV/vis difference spectra recorded over the course of $24 \mathrm{~h}$ for complex $1 \mathrm{a}$ in $\mathrm{CH}_{3} \mathrm{CN}$, pressurized with $70 \mathrm{~atm}$ of $\mathrm{H}_{2}$ gas at room temperature.

We previously determined that the reaction of $1 \mathrm{a}$ with $\mathrm{H}_{2}$ is termolecular, with the hydride $3 \mathrm{a}$ as the presumed product. ${ }^{4}$ We have now quantified the $1 \mathrm{a} / \mathrm{H}_{2}$ equilibrium with the Benesi-Hildebrand method, modified for a ternary equilibrium like that in eqs 2-4 (see the Supporting Information for derivation). ${ }^{8}$ By varying the hydrogen pressure and fitting the absorbance data to eq 4 (Figure 2) we obtain a $\Delta \varepsilon$ of $785 \mathrm{M}^{-1} \mathrm{~cm}^{-}$ 1 and an equilibrium constant $\left(K_{\mathrm{eq}}\right)^{9}$ of $0.014(7)$ atm $^{-1}$.

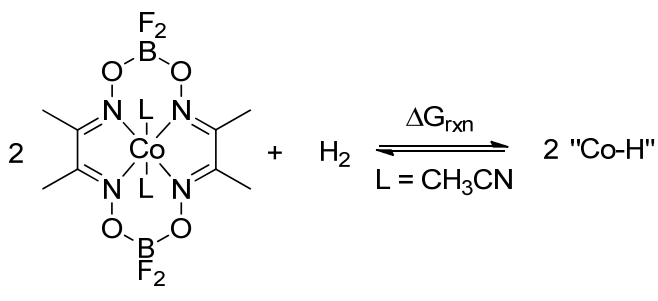

$1 \mathbf{a}$

$$
K_{e q}\left(a t m^{-1}\right)=\frac{\left[" C o-H^{\prime \prime}\right]^{2}}{[1 \mathbf{a}]^{2} P_{H_{2}}}
$$

We can use this value of $K_{\text {eq }}$ to estimate a $\Delta \mathrm{G}_{\mathrm{rxn}}=2.5(3)$ $\mathrm{kcal} / \mathrm{mol}$ for eq 2 . Use of the bond dissociation free energy (BDFE) of $\mathrm{H}_{2}(103.6 \mathrm{kcal} / \mathrm{mol})^{10}$ with eq 6 gives the free energy change of eq $5, \Delta \mathrm{GH}_{\mathrm{H}}=50.5(3) \mathrm{kcal} / \mathrm{mol}^{10}$

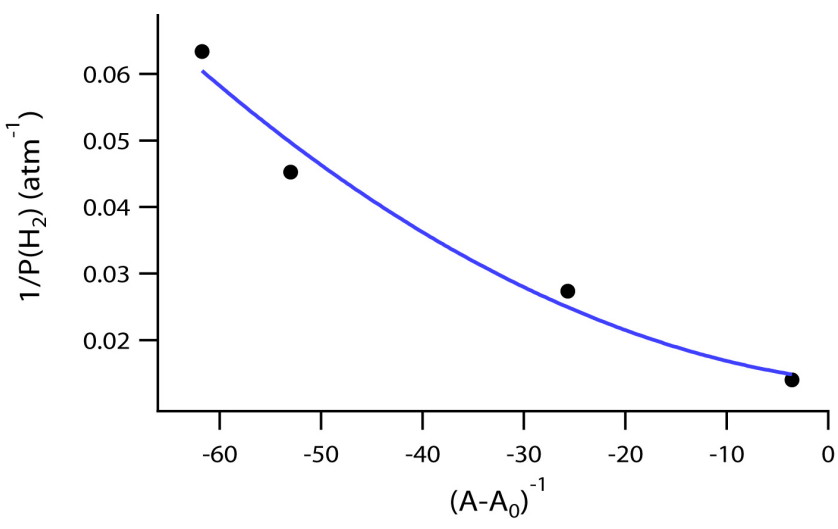

Figure 2. Plot of $\mathrm{P}_{\mathrm{H}_{2}}{ }^{-1}$ vs the inverse of the change in absorbance of $1 \mathrm{a}$ at $434 \mathrm{~nm}\left(\mathrm{~A}-\mathrm{A}_{0}\right)^{-1}$, measured in $\mathrm{CH}_{3} \mathrm{CN}$ under different $\mathrm{H}_{2}$ pressures. The blue curve is a fit of the data to eq 4 .

From the thermodynamic cycle in eq 710 we can estimate the $\mathrm{p} K_{\mathrm{a}}$ of the product as 13.4 in $\mathrm{CH}_{3} \mathrm{CN}$ using the $\Delta \mathrm{G}_{\mathrm{H}}$ from above and the potential of the $\mathrm{Co}(\mathrm{I})^{-} / \mathrm{Co}(\mathrm{II})$ couple $(-0.93 \mathrm{~V}$ vs $\left.\mathrm{Fc} / \mathrm{Fc}^{+}\right) .{ }^{6 \mathrm{~d}}$ Artero and Fontecave observed that the protona- tion of 5 a during $\mathrm{H}_{2}$ evolution occurred with a $\mathrm{p} K_{\mathrm{a}}$ of 13.3 , in good agreement with our estimate. ${ }^{6 \mathrm{~d}}$ This $\mathrm{p} K_{\mathrm{a}}$ is consistent with the facts that (a) proton transfer from $\operatorname{HNEt}_{3}+\left(\mathrm{p} K_{\mathrm{a}}=\right.$ $18.8)^{11}$ to $5 \mathrm{~b}$ is slow and unfavorable (still incomplete after 8 s, Figures S11 and S12), and (b) catalysis of hydrogen evolution by 1 a does not occur with acids weaker than $\mathrm{HNEt}_{3}{ }^{+}$.

$$
\frac{1}{P_{H_{2}}}=K_{\mathrm{eq}}\left(\begin{array}{c}
{[1 \mathrm{a}]_{0}^{2} \Delta \varepsilon^{2}\left(\frac{1}{\mathrm{~A}-\mathrm{A}_{0}}\right)^{2}} \\
-2[1 a]_{0} \Delta \varepsilon\left(\frac{1}{\mathrm{~A}-\mathrm{A}_{0}}\right)+1
\end{array}\right)
$$

$$
\text { "Co-H" } \frac{\Delta \mathrm{G}_{\mathrm{H}}=50.5 \mathrm{kcal} / \mathrm{mol}}{\mathrm{L}=\mathrm{CH}_{3} \mathrm{CN}} \quad G_{H}=\Delta G(H-H)-2 \Delta G_{7}
$$

In order to characterize the product of reaction 2, we monitored the ${ }^{1} \mathrm{H}$ NMR spectrum of $1 \mathrm{a}$ in $\mathrm{CD}_{3} \mathrm{CN}$ under $70 \mathrm{~atm}$ of $\mathrm{H}_{2}$. No signal that could be attributed to $\mathrm{Co}-\mathrm{H}$ was observed, as far upfield as $\delta=-25 \mathrm{ppm}$ (see Figure S8). Of course, residual coupling to the ${ }^{59} \mathrm{Co}$ could broaden the hydride signal and make it difficult to observe. We did see a new resonance (see Figure 3, the full spectrum is in Figure S8) at $\delta 2.06 \mathrm{ppm}$ and a new broad peak at $\delta 2.50 \mathrm{ppm} .^{12}$ The peak at $\delta 2.50 \mathrm{ppm}$ disappeared when the pressure was released. In the presence of exchangeable $\mathrm{D}^{+}$, as in $\mathrm{CD}_{3} \mathrm{OD}$, the $\delta 2.50 \mathrm{ppm}$ signal does not appear (Figure S9), suggesting that it belongs to an exchangeable proton. Both 1a and 2a catalyze H/D exchange between $\mathrm{D}_{2}$ and $\mathrm{H}_{2} \mathrm{O}\left({ }^{1} \mathrm{H}\right.$ NMR in Figure $\mathrm{S} 5,{ }^{2} \mathrm{H}$ NMR in Figure S6).

$6 \mathrm{i}$

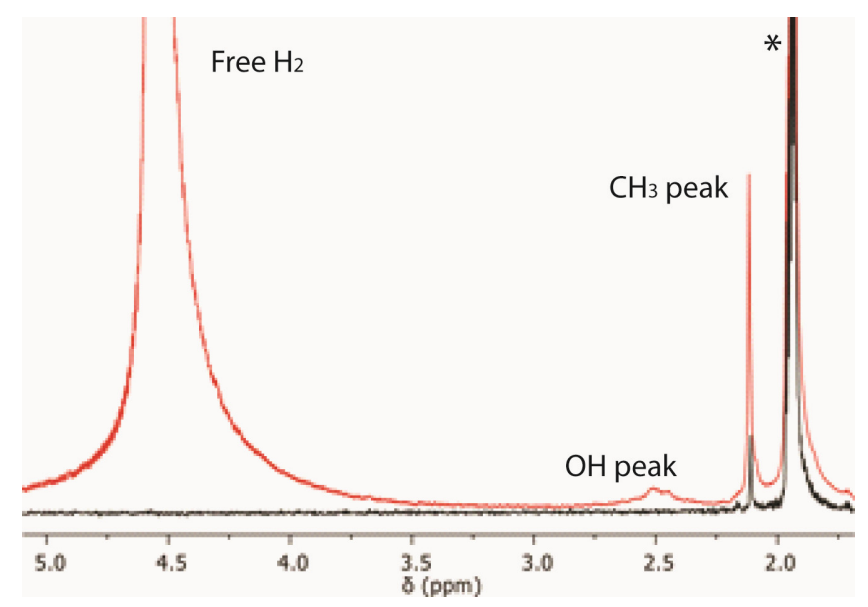

Figure 3. ${ }^{1} \mathrm{H}$ NMR spectra of $1 \mathrm{a}$ in $\mathrm{CD}_{3} \mathrm{CN}$ under $1 \mathrm{~atm}$ of argon (black) and $70 \mathrm{~atm}$ of $\mathrm{H}_{2}$ (red) $\left({ }^{*} \mathrm{CHD}_{2} \mathrm{CN}\right)$

Thus the product of the reaction of 1 a with $\mathrm{H}_{2}$ may not be the cobalt hydride $3 a$. That hydride is probably the first species observed by Dempsey and Gray after protonation of the anion 5a with a photoacid 6 - a species with a high absorb- 
ance at $405 \mathrm{~nm}$. However, as Figure 1 shows, the reaction of $1 \mathrm{a}$ with $\mathrm{H}_{2}$ gives a species (6a) with little absorbance at 405 $\mathrm{nm}$ but peaks at 556 and $627 \mathrm{~nm}$ - a spectrum similar to that of the electrochemically generated Co(I) anion 5a (Figure 4, top).
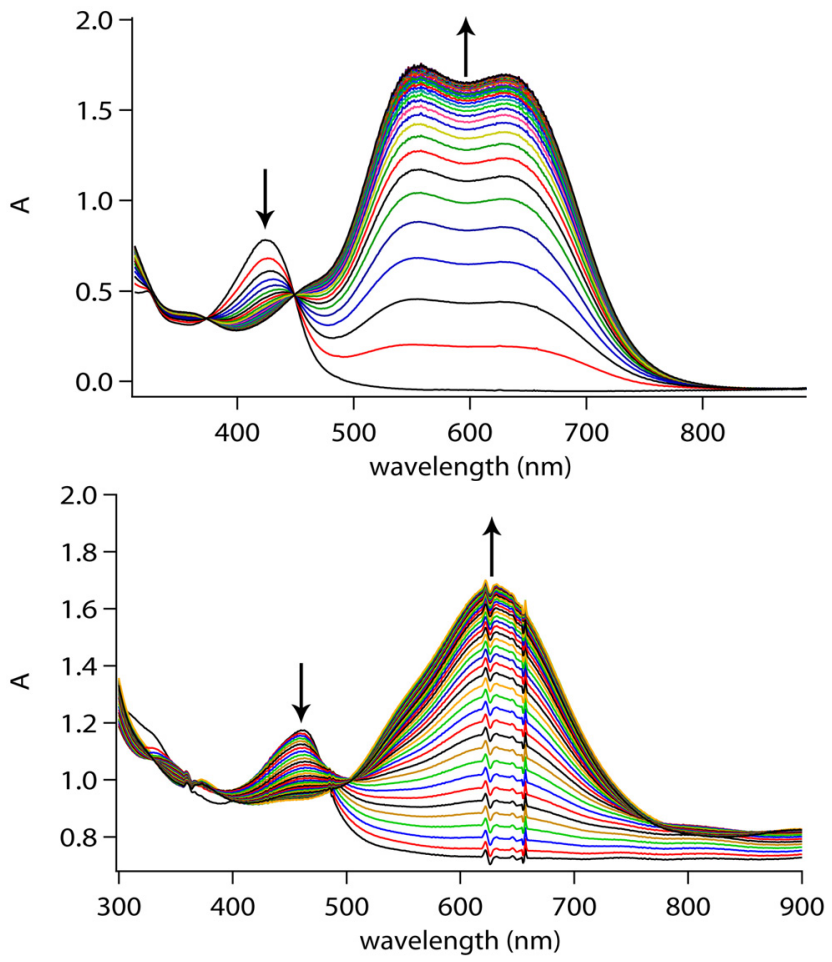

Figure 4. Spectroelectrochemistry of the reduction of 1a in $\mathrm{CH}_{3} \mathrm{CN}$ (top) and $1 \mathrm{~b}$ in THF (bottom) at an applied potential of $-1.0 \mathrm{~V}$ vs $\mathrm{Ag}$ wire. Solutions contain $0.1 \mathrm{M} \mathrm{NBu}_{4} \mathrm{BF}_{4}$ as an electrolyte.

One possible structure for $6 \mathrm{a}-$ which includes a $\mathrm{Co}(\mathrm{I})$ and an exchangeable proton - is drawn in eq 8 below. A similar structure has been suggested by Artero and Fontecave for the mischaracterized " $\mathrm{HCo}(\mathrm{dmgH})_{2} \mathrm{PBu}_{3}$ ". 4,13 The fact that no hydride resonance is observed during reaction 2 in $\mathrm{CH}_{3} \mathrm{CN}$ suggests that $\mathrm{H}_{2}$ activation is rate determining in the formation of $6 \mathrm{a}$ from $1 \mathrm{a}$ and $\mathrm{H}_{2}$, a conclusion supported by measurements of the rate at which $1 \mathrm{a}$ reacts with $\mathrm{H}_{2}{ }^{7}$

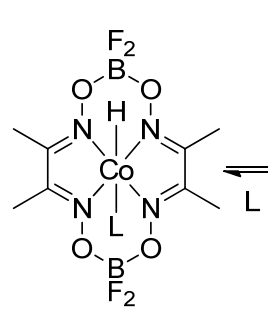

$3 a$

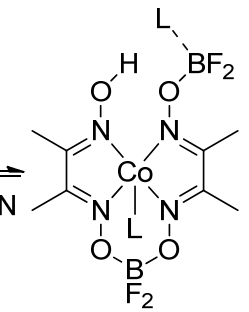

$6 a$
The structure drawn for 6a would have four inequivalent methyls, although we observe only one peak (the one at $\delta 2.06$ $\mathrm{ppm}$ ) in the ${ }^{1} \mathrm{H}$ NMR that can be so assigned. However, it is possible that the proton causing the inequivalence could undergo a proton-coupled electron transfer (PCET) from 6a to $1 \mathrm{a}$ in solution, causing the methyl groups to exchange with each other on the NMR time scale (Scheme 3). This would produce a spectrum with only one methyl peak. When we lower the temperature of the pressurized sample (Figure $\mathrm{S} 10$ ), the pressure of $\mathrm{H}_{2}$, and thus the amount of $\mathrm{H}_{2}$ dissolved in the solution, decreases (as indicated by the intensity of the free $\mathrm{H}_{2}$ peak in the NMR), and the chemical shift of the supposed methyl signal at $2.06 \mathrm{ppm}$ increases. This presumably increases the ratio of $1 \mathrm{a}$ to $6 \mathrm{a}$ in solution, causing simultaneous broadening and shifting of the methyl resonance while the position and shape of the proton at $2.5 \mathrm{ppm}$ remains the same.

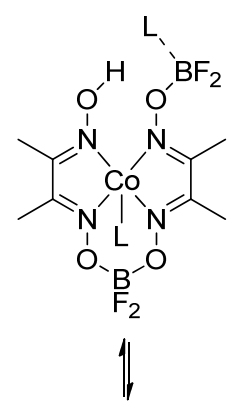

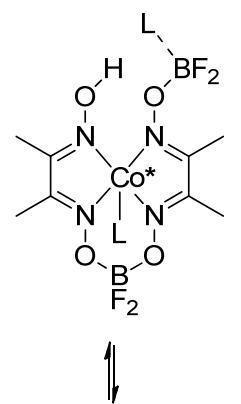

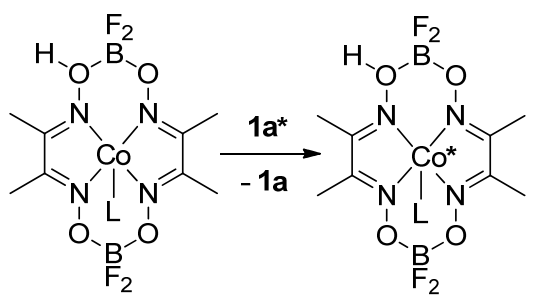

Scheme 3. Possible mechanism of PCET between 6a and 1a.

We also monitored the UV-vis spectrum of a solution of $\mathrm{Co}\left(\mathrm{dmgBF}_{2}\right)_{2}(\mathrm{THF})_{2}$ (1b) under $70 \mathrm{~atm} \mathrm{H}_{2}$ in THF (Figure 5). Over the course of $8 \mathrm{~h}$ we observed bleaching of the signal at $430 \mathrm{~nm}$ in conjunction with the appearance of new peaks at 354 and $305 \mathrm{~nm}$. After $8 \mathrm{~h}$, a third species grew in at $580 \mathrm{~nm}$, as the $354 \mathrm{~nm}$ absorbance decreased.

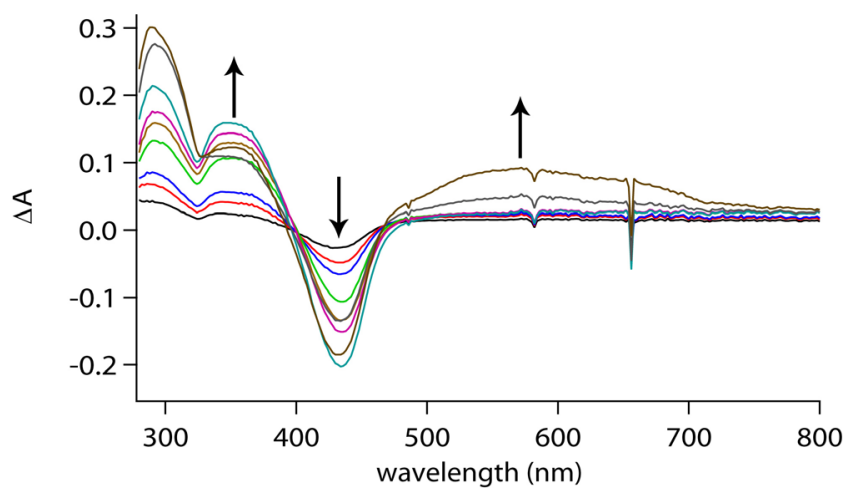

Figure 5. UV/vis difference spectra recorded over the course of $24 \mathrm{~h}$ for complex $\mathbf{1 b}$ in THF pressurized with $70 \mathrm{~atm}$ of $\mathrm{H}_{2}$ gas at room temperature.

The absorbance of the intermediate in THF (354 nm) is similar to that observed for $\mathrm{Co}\left(\mathrm{dmgBF}_{2}\right)_{2}\left(\mathrm{CH}_{3} \mathrm{CN}\right) \mathrm{Me}^{6 i}$ similar to the spectrum calculated for $3 a^{14}$ and similar to the absorbance observed by Dempsey and Gray which they attributed to 3. ${ }^{6 \mathrm{i}}$ We believe that in THF the intermediate at $354 \mathrm{~nm}$ is the hydride complex $3 b-$ presumably the initial product of the termolecular reaction with hydrogen. ${ }^{15}$ We have not been able to look for a hydride resonance in he NMR spectra in THF because of the low solubility of $1 \mathrm{~b}$ in that solvent. The subsequent $580 \mathrm{~nm}$ absorbance may be due to a tautomerized product, similar to $6 \mathrm{a}$. This $580 \mathrm{~nm}$ peak is shifted relative to the $630 \mathrm{~nm}$ peak seen for the $\mathrm{Co}(\mathrm{I})$ anion $5 \mathrm{~b}$ (Figure 4, bottom). This could be the result of different populations of the open and closed forms of $6 \mathrm{~b}$ shown in Scheme 3. Changing the 
axial ligand from $\mathrm{CH}_{3} \mathrm{CN}$ to THF may change the $\mathrm{p} K_{\mathrm{a}}$ of the hydride (3) enough to slow down its tautomerization.

A tautomerized product, like 6a, could explain some observations in the hydrogen evolution literature that were originally attributed to hydride 3a. Compound 6 may be the kinetic product of protonation of 5 . Upon rapid mixing of $5 \mathrm{c}$ with acid, Bakac and co-workers observed an intermediate with $\lambda_{\max }$ at $610 \mathrm{~nm}$, similar to that of $5 \mathrm{c}$ but less intense $\left(10^{4} \mathrm{M}^{-1} \mathrm{~cm}^{-1}\right){ }^{6 \mathrm{f}}$ They attributed this feature to the hydride $3 c$, but given the spectrum observed for the hydride 3a by Dempsey and Gray (high absorbance at $405 \mathrm{~nm}$ ), we question this assignment, and propose that the Bakac spectrum may be due to the ligand-protonated complex $6 \mathrm{c}$ (the spectra are quite similar). However, during the photochemical protonation of $\mathbf{5 a}$, Gray and coworkers observed direct protonation of the metal.6i Bakac's experiment was done with excess citrate present, which could coordinate to the boron and make the ligand's oxygen available for protonation. The citrate could also catalyze the proton transfer necessary for the conversion of 6 a to $3 \mathrm{a}$, in the way Bullock and DuBois observe for $\left[\mathrm{Ni}\left(\mathrm{P}_{2} \mathrm{~N}\right)_{2}\right]^{2+}$ complexes. ${ }^{16}$

In summary, in $\mathrm{CH}_{3} \mathrm{CN}$ under large pressures of $\mathrm{H}_{2}$, cobaloxime $1 \mathrm{a}$ is converted to a product, $6 \mathrm{a}$, having a $\mathrm{Co}(\mathrm{I})$ center and an exchangeable proton, which is possibly a tautomer of the hydride 3a. In THF, however, the major product under high hydrogen pressures may well be the hydride $3 \mathrm{~b}$. This difference in reactivity is most likely due to the hydride $3 \mathrm{~b}$ being less acidic than $3 \mathrm{a}$. The free energy of $\mathrm{H} \bullet$ donation and the $\mathrm{p} K_{\mathrm{a}}$ of $6 \mathrm{a}$ are $50.5 \mathrm{kcal} / \mathrm{mol}$ and 13.4 , respectively. However, the assignment of the position of the proton on the ligand cannot conclusively be determined from the data presented.

It is possible that the same hydride tautomer is an intermediate in the mechanism of electrocatalytic hydrogen gas production by cobaloximes. It may be the cause of the difficulty in characterizing cobaloxime hydrides in these reactions.

\section{ASSOCIATED CONTENT}

\section{Supporting Information}

Experimental detail, NMR data, UV-vis data, derivation of eq 6, stopped flow data.

\section{AUTHOR INFORMATION}

\section{Corresponding Author}

*3000 Broadway MC 3102, New York, NY 10027 , (212)854-7649,jrn11@columbia.edu

The authors declare no competing financial interests.

\section{ACKNOWLEDGMENT}

Support for this work was provided by the Department of Energy (DE-FG02-97ER14807). We also thank Boulder Scientific and OFS Fitel for support. D.E. was supported by the Department of Energy Office of Science Graduate Fellowship Program (DOE SCGF), made possible in part by the American Recovery and Reinvestment Act of 2009, administered by ORISE-ORAU under contract no. DE-AC05-06OR23100. The work at BNL was supported by the U.S. Department of Energy, Office of Science, Office of Basic Energy Sciences, Division of Chemical Sciences, Geosciences \& Biosciences, under contract \# DE-AC0298CH10886. We would like to thank Etsuko Fujita and Andreja Bakac for helpful discussions.

\section{REFERENCES}

1. (a) Schrauzer, G. N.; Sibert, J. W. J. Am. Chem. Soc. 1970, 92, 1022; (b) Schrauzer, G. N. Inorg. Synth. 1968, 11, 61.

2. (a) Razavet, M.; Artero, V.; Fontecave, M. Inorg. Chem. 2005, 44, 4786; (b) Hu, X.;

Cossairt, B. M.; Brunschwig, B. S.; Lewis, N. S.; Peters, J. C. Chem. Commun. 2005, 4723; (c) Chao, T.-H.; Espenson, J. H. J. Am. Chem. Soc. 1978, 100, 129.

3. (a) Simándi, L. I.; Szeverényi, Z.; BudóZáhonyi, É. Inorg. Nucl. Chem. Letters 1975, 11, 773; (b) Simándi, L. I.; Budó-Záhonyi, É.;

Szeverényi, Z. Inorg. Nucl. Chem. Lett. 1976, 12, 237; (c) Simándi, L. I.; Budó-Záhonyi, É.; Szeverényi, Z.; Németh, S. J. Chem. Soc., Dalton Trans. 1980, 276.

4. Li, G.; Han, A.; Pulling, M. E.; Estes, D. P.; Norton, J. R. J. Am. Chem. Soc. 2012, 134, 14662.

5. $\quad$ Estes, D. P.; Norton, J. R.; Jockusch, S.; Sattler, W. J. Am. Chem. Soc. 2012, 134, 15512. 6. (a) Du, P.; Knowles, K.; Eisenberg, R. J. Am. Chem. Soc. 2008, 130, 12576; (b) Du, P.; Schneider, J.; Luo, G.; Brennessel, W. W.; Eisenberg, R. Inorg. Chem. 2009, 48, 4952; (c) Hu, X. L.; Brunschwig, B. S.; Peters, J. C. J. Am. Chem. Soc. 2007, 129, 8988; (d) Baffert, C.;

Artero, V.; Fontecave, M. Inorg. Chem. 2007, 46, 1817; (e) Fihri, A.; Artero, V.; Razavet, M.; Baffert, C.; Leibl, W.; Fontecave, M. Angew. Chem., Int. Ed. 2008, 47, 564; (f) Szajna-Fuller, E.; Bakac, A. Eur. J. Inorg. Chem. 2010, 2488; (g) Dempsey, J. L.; Brunschwig, B. S.; Winkler, J. R.; Gray, H. B. Acc. Chem. Res. 2009, 42, 1995, and references therein; (h) Dempsey, J. L.; Winkler, J. R.; Gray, H. B. J. Am. Chem. Soc. 2010, 132, 1060; (i) Dempsey, J. L.; Winkler, J. R.; Gray, H. B. J. Am. Chem. Soc. 2010, 132, 16774, and references therein.

7. Li, G.; Estes, D. P.; Norton, J. R.; Ruccolo, S.; Sattler, A.; Sattler, W. Inorg. Chem. 2014, $A S A P$.

8. Drago, R. S., Physical Methods for Chemists, 2nd Ed. Saunders College Publishing: 1992.

9. Purwanto; Deshpande, R. M.; Chaudhari, R. V.; Delmas, H. J. Chem. Eng. Data 1996, 41, 1414. We calculated $K_{\text {eq }}$ using a standard state of 
$1 \mathrm{M}$ in $\mathrm{H}_{2}$. The Henry's law constant for $\mathrm{H}_{2}$ in acetonitrile is $284.1 \mathrm{~atm} \mathrm{M}$.

10. Wayner, D. D. M.; Parker, V. D. Acc.

Chem. Res. 1993, 26, 287.

11. Kaljurand, I.; Kutt, A.; Soovali, L.;

Rodima, T.; Maemets, V.; Leito, I.; Koppel, I. A.

J. Org. Chem. 2005, 70, 1019.

12. The extremely large absorbance of $\mathrm{H} 2$ in

the NMR spectrum causes truncation errors in the

FID of these spectra. This produces a "rippling"

effect radiating from the edges of the $\mathrm{H} 2$ peak.

This causes large errors in the integral of the broad peak at $2.50 \mathrm{ppm}$ and thus the ratio of the peak at $2.5 \mathrm{ppm}$ to that at $2.06 \mathrm{ppm}$, with observed ratios being between $1: 4$ and $1: 15$. The spectrum with the least $\mathrm{H} 2$ (at $243 \mathrm{~K}$ ) had the least truncation error and with the integral of the peak at 2.50 ppm being 0.82 .

13. Bhattacharjee, A.; Chavarot-Kerlidou, M.; Andreiadis, E. S.; Fontecave, M.; Field, M. J.;

Artero, V. Inorg. Chem. 2012, 51, 7087.

14. Muckerman, J. T.; Fujita, E. Chem.

Commun. 2011, 47, 12456.

15. Norton, J. R.; Spataru, T.; Camaoni, D.; Lee, S.-J.; Li, G.; Choi, J.; Franz, J. A.

Organometallics 2014, 33, 2496.

16. Helm, M. L.; Stewart, M. P.; Bullock, R. M.; DuBois, M. R.; DuBois, D. L. Science 2011, 333, 863.

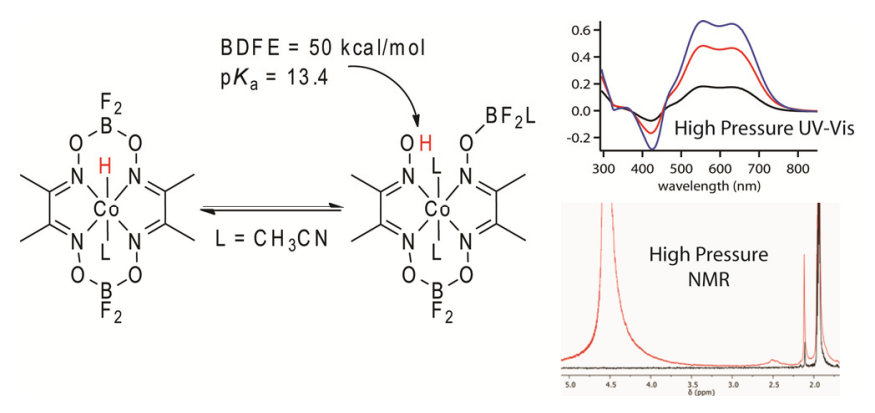

